\title{
PENGARUH GAYA KEPEMIMPINAN DAN MOTIVASI TERHADAP KINERJA KARYAWAN PADA HOTEL KAYUMANIS UBUD PRIVATE VILLA \& SPA GIANYAR
}

\author{
Luh Komang Handani ${ }^{1}$ \\ Desak Gede Sayang Adnyani ${ }^{2}$ \\ Fakultas Ekonomi Ngurah Rai Denpasar \\ Email: luhhandani@gmail.com
}

\begin{abstract}
ABSTRAK
Keberhasilan seluruh pelaksanaan tugas-tugas kerja suatu perusahaan sangat ditentukan oleh tersediannya sumber daya manusia yang berkualitas. Salah satu pendekatan dalam upaya meningkatkan kinerja karywan tersebut dapat dilakukan melalui praktik gaya kepemimpinan dan motivasi yang sesuai. Adanya perhatian dan ditemui permasalahan berkaitan dengan gaya kepemimpinan dan motivasi dalam usaha meningkatkan kinerja karyawan maka sangat layak dalam penelitian ini diteliti lebih jauh lagi pengaruh gaya kepemimpinan dan motivasi terhadap kinerja karyawan pada hotel kayumanis ubud private villa \& spa gianyar.

Hasil analisis regresi berganda yaitu $\mathrm{Y}=1,382+0,516 \mathrm{X}_{1}+0,458 \mathrm{X}_{2}$. variabel Gaya kepemimpinan (6,820), diikuti motivasi $(6,745)$. Hasil uji t membuktikan variabel Gaya Kepemimpinan dan Motivasi berpengaruh positif dan signifikan secara parsial dan simultan terhadap variabel Kinerja Karyawan pada Kayumanis Ubud Private Villa \& Spa Gianyar. Artinya menurut karyawan, kedua variabel independen dianggap penting untuk Kinerja Karyawan pada Kayumanis Ubud Private Villa \& Spa Gianyar. Nilai koefisien determinasi sebesar 0,873 menunjukkan bahwa perubahan gaya kepemimpinan dan motivasi secara simultan berkontribusi terhadap perubahan kinerja karyawan sebesar $87,3 \%$.
\end{abstract}

Kata Kunci : Gaya Kepemimpinan, Motivasi dan Kinerja Karyawan

\section{ABSTRACT}

The success of all execution duties of a company is determined by the availability of qualified human resources. One approach to improving the employee's performance can be done through appropriate leadership style and motivation practices. The attention and problems encountered related to the style of leadership and motivation in an effort to improve employee performance is very feasible in this study further studied the influence of leadership style and motivation on employee performance at hotel kayumanis ubud private villa \& spa gianyar. The result of multiple regression analysis is $Y=1,382+0,516 X 1+0,458 X 2$. Variable leadership style $(6,820)$, followed by motivation (6,745). Result of t test to prove the variable of Leadership Style and Motivation have positive and significant influence partially and simultaneously to Employee Performance variable at Kayumanis Ubud Private Villa \& Spa Gianyar. This means that according to employees, the two independent variables are considered important for Employee Performance at Kayumanis Ubud Private Villa \& Spa Gianyar. The value of determination coefficient of 0.873 shows that changes in leadership style and motivation simultaneously contribute to the change in employee performance of $87.3 \%$.

Keywords: Leadership Style, Motivation and Employee Performance 


\section{PENDAHULUAN}

Sumber daya manusia adalah aset yang sangat penting bagi sebuah organisasi.Keberhasilan suatu organisasi sangat ditentukan oleh kualitas sumber daya manusia yang ada didalamnya, karena untuk pencapaian setiap tujuan organisasi dipengaruhi oleh perilaku organisasi itu sendiri.Pentingnya keberadaan sumber daya manusia dalam pengembangan usaha jasa pariwisata, terlihat dari kemampuan suatu perusahaan untuk berkembang sangat bergantung pada kemampuan sumber daya manusia untuk memanfaatkan sumber daya yang ada di perusahaan untuk melaksanakan tugas-tugas kerja dalam kerangka kerja yang terarah untuk pengembangan organisasi.

Keberhasilan seluruh

pelaksanaan tugas-tugas kerja suatu perusahaan sangat ditentukan oleh tersedianya sumber daya manusia yang berkualitas.Dengan dukungan sumber daya manusia yang berkualitas, tentunya diharapkan berperan aktif sebagai perencana, pelaksana sekaligus sebagai pengawas terhadap semua kegiatan manajemen perusahaan.fungsi sumber daya manusia di dalam perusahaan harus mampu untuk menjadi mitra kerja yang dapat diandalkan, baik oleh para pimpinan puncak perusahaan, maupun manajer lini. Faktor sumber daya manusia didalam ruang lingkup suatu perusahaan merupakan faktor penting yang harus diperhatikan, sebabSalah satu faktor penting dalam sebuah perusahaan adalah pegawai perusahaan itu sendiri, pegawai merupakan asset penting yang wajib mereka jaga.Tidak terkecuali bagi perusahaan yang khususnya bergerak di bidang pariwisata.Perusahaan tersebut tentu saja mengandalkan tingkat kinerja pegawai di perusahaannya.Menurut Mangkunegara (2013:67), Kinerja adalah hasil kerja secara kualitas dan kuantitas yang dicapai oleh seorang pegawai dalam melaksanakan tugasnya sesuai dengan tanggung jawab yang diberikan kepadanya, maka perusahaan juga dituntut untuk mampu mengoptimalkan kinerja pegawainya, guna tercapai tujuan perusahaan secara maksimal.

Salah satu pendekatan dalam upaya meningkatkan kinerja pegawai tersebut dapat dilakukan melalui praktik gaya kepemimpinan yang sesuai, gaya kepemimpinan adalah salah satu faktor yang berdampak besar untuk mencapai tujuan dalam organisasi. Kualitas hubungan antara pemimpin dengan bawahannya sangat penting dalam berbagai hal untuk memastikan kualitas performa dalam pekerjaannya. Dengan gaya kepemimpinan serta karakter pemimpin yang berbeda akan memberi dampak yang berbeda pula dalam suatu organisasi. Dalam menghadapi tingkat persaingan usaha yang tinggi, maka Kayumanis Ubud Private Villa \& Spa Gianyar harus bisa mempertahankan kelangsungan kegiatan perusahaan agar tetap lancar dan dapat meningkatkan daya saing, untuk memberikan gaya kepemimpinan yang tepat serta motivasi kerja karyawannya. Maka dapat dipastikan bahwa perilaku seorang pemimpin adalah pengaruh yang akan menimbulkan pemahaman tersendiri yang akan berpengaruh terhadap kondisi psikologis bawahan. Apabila perilaku kepemimpinan yang ditampilkan atasan dirasa sebagai suatu yang diharapkan bawahan maka akan memiliki dampak yang lebih baik terhadap kinerja karyawan, begitupula 
sebaliknya apabila perilaku kepemimpinan yang ditampilkan atasan sebagai sesuatu yang tidak sesuaidengan harapan para bawahan maka akan berpengaruh kurang baik terhadap kinerja para karyawan.

Seperti yang disampaikan oleh Wilson Bangun (2011:123), Gaya kepemimpinan merupakan proses memengaruhi dan menginspirasi orang lain untuk bekerja demi mencapai tujuan utama dan kemudian dapat memberikan kekuatan dan kebebasan untuk mencapainya.

Gaya kepemimpinan dapat berupa teknik untuk mengatur manajemen sumber daya manusia. Seorang pemimpin dalam organisasi harus dapat menciptakan integrasi yang serasi dengan para bawahannya juga termasuk dalam membina kerjasama, mengarah dan mendorong gairah kerja para bawahannya sehingga tercipta motivasi positif yang akan menimbulkan niat dan usaha (kinerja) yang maksimal juga didukung oleh fasilitas-fasilitas organisasi untuk mencapai sasaran organisasi.

Selain gaya kepemimpinan yang diterapkan, motivasi juga merupakan faktor yang mempengaruhi kinerja karyawan. Seorang pemimpin harus mampu memberikan motivasi kepada bawahan agar dapat bekerja dengan baik dan efektif. Feriyanto dan Shyta (2015:78), menyatakan, pemimpin mempunyai kaitan yang erat dengan motivasi, sebab keberhasilan seorang pemimpin dalam menggerakkan orang lain dalam mencapai tujuan yang telah ditetapkan sangat bergantung kepada kewibawaan, dan juga pemimpin itu menciptakan motivasi di dalam diri setiap orang bawahan, kolega maupun atasan pemimpin itu sendiri. Ada banyak faktor yang dapat memengaruhi dan membuat suatu perusahaan dapat berjalan dengan baik dan tercapai tujuan dari perusahaan tersebut, di antaranya yaitu motivasikerja karyawan dan kinerja karyawan yang baik dan meningkat setiap harinya, termasuk pada perusahaan yang bergerak di bidang pariwisata yaitu Kayumanis Ubud Private Villa \& Spa Gianyar.

Berdasarkan observasi dan wawancara masih ditemukannya keluhan karyawantentang gaya kepemimpinan salah satunya tentang pemimpin kurang jelas dalam menjelaskan pedoman kerja kepada karyawan sehingga perintah atau instruksi yang diberikan oleh pimpinan kurang diterima dengan baik oleh bawahan dan pimpinan yang kurang mengayomi sehingga karyawan merasa pimpinan kurang tegas dan bijaksana dalam memperlakukan karyawan, serta partisipasi karyawan dalam pengambilan keputusan dan penentuan kebijakan masih sangat minim sehingga keluhan yang dirasakan serta saran dari karyawan tidak tersalurkan dengan baik.

Kayumanis Ubud Private Villa \& Spa Gianyar merupakan perusahaan swasta yang bergerak pada bidang pariwisata yang mempekerjakan $163 \quad$ orang karyawan.Untuk meningkatkan kinerja karyawannya, maka Kayumanis Ubud Private Villa \& Spa memandang penting pemberian motivasi yang tepat agar kinerja karyawan semakin meningkat.Ada dua metode pemberian motivasi yang lazim dipakai yaitu langsung dan tidak langsung,salah satumotivasi yang diberikan pihak hotel kepada karyawan adalah motivasi langsung berupa gaji atau 
insentif.Jumlah Gaji yang diterima karyawan pada tahun 2016 rata-rata jumlah penerimaan perorangan bisa mencapai $\quad$ Rp. $\quad 3.000 .000$ perbulannya.Besar kecilnya gaji yang diterima dipengaruhi oleh jabatan yang dipegang,besarnya gaji yangdiberikan pada tahun 2016mengacu pada Upah Minimum Kabupaten/Kota (UMK) Gianyar sebesar Rp.1.904.141,berdasarkan Peraturan Gubernur Bali No 69 tahun 2014.

Gaji yang diterima oleh karyawan sudah melebihi umk tetapi setelah melakukan observasi, serta melakukan wawancara masih ada beberapa keluhan karyawan salah

Selain motivasi yang diberikan, berikut data mengenai jumlah pengunjung satunya yang sudah berkeluarga mengenai motivasi berupa gaji yang diberikan kurang, mungkin disebabkan karena kewajiban memenuhi kebutuhan mereka semakin bertambah setelah berkeluarga dan beban kerja yang mereka terima tidak sesuai.Selain itu pemberian gaji atau insentifsebagai motivasi untuk karyawan lebih sering tidak tepat waktu, terlambat 1 atau 3 hari dari waktu yang ditetapkan, akibatnya karyawan kurang termotivasi atau terdorongan untuk bekerja lebih maksimal sehingga hasil yang dicapai tidak sesuai dengan target yang direncanakan oleh perusahaan. yang menginap pada kayumanis Ubud Private Villa \& Spa Gianyar dapat dilihat pada table 1di bawah ini :

Tabel 1Jumlah Pengunjung Yang Menginap Pada Kayumanis Ubud Private Villa \& Spa Gianyar.

\begin{tabular}{cc}
\hline Tahun & Jumlah Pengunjung \\
\hline 2015 & 10.977 \\
2016 & 13.518 \\
2017 & 8.893 \\
\hline
\end{tabular}

Sumber : Kayumanis Ubud Private Villa \& Spa Gianyar.

Berdasarkan data pada tabel 1 , terlihat bahwa pencapaian tingkat pengunjung yang menginap di Kayumanis Ubud Private Villa \& Spa Gianyar pada tiap tahunnya bersifat fluktuatif. Penurunan yang signifikan terjadi padatahun 2017, jumlah pengunjung tertinggi terjadi pada tahun 2016. Penurunan jumlah pengunjung yang terjadikarena adanya indikasi penurunan kualitaspelayanan yang diberikan, Penurunan yang terjadi juga disertai dengan dipengaruhi oleh kondisi Gunung Agung.Pihak pimpinan hotel telah memberlakukan sistem kerja secara bergilir bagi karyawan yaitu memberlakukan jadwal 15 hari kerja, jumlah pengunjung sangat besar pengaruhnya terhadap kelangsungan hidup perusahaan terutama bagi karyawan.Semakin banyak pengunjung maka semakin banyak pemasukan yang diraih, tetapi 
sebaliknya semakin sedikitnya pengunjung, maka semakin melemahnya kinerja karyawan untuk mendapatakan pemasukan yang diraih.

Dengan timbulnya masalahmasalah tersebut tentunya berdampak pada kinerja karyawan, dengan melemahnya kinerja karyawan, karyawan merasadirinya tidak akan puas dalam melaksanakan pekerjaannya sehingga tujuandaripada perusahaan tidak akan tercapai dengan baik pula.

Berdasarkan latar belakang yang telah diuraikan, yang menjadi METODE PENELITIAN

Penelitian ini berlokasi pada Hotel Kayumanis Ubud Private Villa \& Spa Gianyar yang terletak di jalan raya Sayan Br. Baung, Ubud Gianyar - Bali. Adapun yang menjadi objek penelitian ini adalah pegawai Kayumanis Ubud Private Villa \& Spa Gianyar adalah mengenai gaya kepemimpinan, motivasi serta kinerja karyawan. Sumber data dalam penelitian ini adalah data primer yang diperoleh secara langsung dari responden dan sekunder yang diperoleh dari bahan perpustakaan dan penelitian secara tidak langsung.Responden penelitian didapat dengan menggunakan metode slovin dengan jumlah 116 responden.Metode pengumpulan data rumusan masalah pada penelitian ini adalah :

a. Bagaimana gaya kepemimpinan dan motivasi berpengaruh secara parsial terhadap kinerja karyawan pada Kayumanis Ubud Private Villa \& Spa Gianyar?

b. Bagaimana gaya kepemimpinan dan motivasi berpengaruh secara simultan terhadap kinerja karyawan pada Kayumanis Ubud Private Villa \& Spa Gianyar? yang dipergunakan ialah observasi, wawancara, kuisioner dan dokumentasi.Teknik analisis data kuantitatif meliputi analisis regresi linier berganda, analisis determinasi, uji parsial (uji-t) dan uji simultan (ujiF) dengan menggunakan program SPSS.

HASIL DAN PEMBAHASAN

Teknik analisis regresi linier berganda yang dipergunakan dalam penelitian ini adalah agar dapat melihat hubungan antara variabel bebas dengna variabel terikat.Berdasarkan hasil analisis data yang telah dilakukan dapat dilihat pada tabel 2 . 
Tabel 2

Coefficients $^{\mathrm{a}}$

\begin{tabular}{|c|c|c|c|c|c|}
\hline \multirow[b]{2}{*}{ Model } & \multicolumn{2}{|c|}{$\begin{array}{c}\text { Unstandardized } \\
\text { Coefficients }\end{array}$} & \multirow{2}{*}{$\begin{array}{c}\text { Standardized } \\
\text { Coefficients }\end{array}$} & \multirow[t]{2}{*}{$\mathrm{T}$} & \multirow[t]{2}{*}{ Sig. } \\
\hline & $\mathrm{B}$ & Std. Error & & & \\
\hline $1 \quad$ (Constant) & 1.382 & 1.409 & & .981 & .329 \\
\hline Gaya Kepemimpinan & .516 & .076 & .484 & 6.820 & .000 \\
\hline Motivasi & .458 & .068 & .479 & 6.745 & .000 \\
\hline
\end{tabular}

Berdasarkan Tabel 2, maka rumusan regresi linier berganda yaitu: $\mathrm{Y}=1,382+0,516 X_{1}+0,458 X_{2}$

(1)

Dari persamaan tersebut dapat diinterpretasikan sebagai berikut:

$$
\begin{aligned}
\mathrm{a}= & 1,382 \text { artinya apabila gaya } \\
& \text { kepemimpinan }\left(X_{1}\right) \text { dan } \\
& \text { motivasi }\left(X_{2}\right) \text { masing- } \\
& \text { masing memiliki nilai nol } \\
& \text { maka nilai } Y \text { sebesar } 1,382
\end{aligned}
$$

$$
\begin{aligned}
b_{1}= & 0,516 \text { artinya apabila gaya } \\
& \text { kepemimpinan } \\
& \text { dinaikkan satu-satuan, maka } \\
& \text { Y akan meningkat sebesar } \\
& 0,516, \text { dengan asumsi } \\
& \text { variable motivasi }\left(X_{2}\right) \\
& \text { konstan. }
\end{aligned}
$$$$
b_{2}=0,458 \text { artinya apabila motivasi }
$$
$\left(X_{2}\right)$ dinaikkan satu-satuan, maka $\mathrm{Y}$ akan meningkat sebesar 0,458, dengan asumsi variable gaya kepemimpinan $\left(X_{1}\right)$ konstan.

\section{Analisis Determinasi}

Analisis determinasi digunakan untuk mengetahui variasi hubungan antara Gaya Kepemimpinan dan Motivasi terhadap Kinerja Karyawan yang dinyatakan dalam persentase.maka digunakan koefisien determinasi yang dapat dilihat pada tabel 3 .

Tabel 3

Model Summary ${ }^{\mathrm{b}}$

\begin{tabular}{|l|r|r|r|c|}
\hline Model & \multicolumn{1}{|c|}{$\mathrm{R}$} & R Square & \multicolumn{1}{c|}{$\begin{array}{c}\text { Adjusted R } \\
\text { Square }\end{array}$} & $\begin{array}{c}\text { Std. Error of the } \\
\text { Estimate }\end{array}$ \\
\hline 1 & $.934^{\mathrm{a}}$ & .873 & .871 & 2.28109 \\
\hline
\end{tabular}

Berdasarkan hasil perhitungan dengan bantuan program SPSS pada tabel 3 diatas diperoleh nilai koefisien determinasi $(\mathrm{R}$
Square)adalah $\quad$ 0,873.Ini berarti besarnya variasi pengaruh Gaya Kepemimpinan dan Motivasi terhadap Kinerja Karyawan adalah 
sebesar $87,3 \%$, sedangkan sisanya $12,7 \%$ ditentukan oleh variabel lain diluar Gaya Kepemimpinandan Motivasi yang tidak dibahas dalam penelitian ini.

\section{Analisis Uji t (t-test)}

Uji signifikansi parsial (t-test) digunakan untuk menguji signifikansi koefisien regresi, sehingga diketahui pengaruh secara parsial antara gaya kepemimpinan dan motivasi terhadap kinerja karyawanadalah pengaruh yang positif dan signifikan (nyata) atau hanya diperoleh secara kebetulan.

\section{1) Pengaruh}

Gaya

Kepemimpinan $\left(X_{1}\right)$ terhadap Kinerja Karyawab (Y)pada Kayumanis Ubud Private Villa \& Spa Gianyar.

Berdasarkan hasi analisis yang dilakukan dengan menggunakan program

SPSS, dapat diketahui nilai $t_{1-\text { hitung }}$ $=6,820>t_{\text {tabel }}=1,658$ dan nilai signifikan sebesar $0,000<\alpha=0,05$, maka ada pengaruh positif dan signifikan antara Gaya Kepemimpinan terhadap Kinerja Karyawan secara parsial pada
Kayumanis Ubud Private Villa \& Spa Gianyar.

2) Pengaruh $\operatorname{Motivasi}\left(X_{2}\right)$ terhadap Kinerja Karyawab (Y)pada Kayumanis Ubud Private Villa \& Spa Gianyar.

Berdasarkan hasi analisis yang dilakukan dengan menggunakan program

SPSS, dapat diketahui nilai $t_{2-\text { hitung }}$ $=6,745>t_{\text {tabel }}=1,658$ dan nilai signifikan sebesar $0,000<\alpha=0,05$, maka ada pengaruh positif dan signifikan antara Motivasi terhadap Kinerja Karyawan secara parsial pada Kayumanis Ubud Private Villa \& Spa Gianyar.

\section{Analisis Uji F (F-test)}

Uji ini digunakan untuk menguji signifikansi nilai koefisien regresi sehingga diketahui apakah ada pengaruh secara simultan antara gaya kepemimpinan dan motivasi kerja terhadap kinerja karyawanberpengaruh positif dan signifikan atau hanya diperoleh secara kebetulan, dengan derajat keyakinan sebesar $95 \%$ dan tingkat kesalahan $5 \%$.

Tabel 4

ANOVA $^{\mathrm{a}}$

\begin{tabular}{|c|c|c|c|c|c|}
\hline Model & Sum of Squares & $\overline{\mathrm{Df}}$ & Mean Square & $F$ & Sig. \\
\hline $1 \quad$ Regression & 4038.052 & 2 & 2019.026 & 388.022 & $.000^{\mathrm{b}}$ \\
\hline Residual & 587.983 & 113 & 5.203 & & \\
\hline Total & 4626.034 & 115 & & & \\
\hline
\end{tabular}

Berdasarkan Tabel 4, diketahui bahwa $F_{\text {hitung }}$ dalam penelitian ini adalah 388,022 sedangkan $F_{\text {tabel }}$ didapatkan 3,08 dengan tingkat signifikansi sebesar $0,000<\alpha=0,05$, maka ada pengaruh positif dan signifikan antara Gaya Kepemimpinan dan Motivasi terhadap Kinerja Karyawan secara secara simultan. 


\section{Pengaruh Gaya Kepemimpian terhadap Kinerja Karyawan}

Secara parsial dalam penelitian ini menunjukkan adanya pengaruh positif dan signifikan antara Gaya Kepemimpinan $\left(\mathrm{X}_{1}\right)$ terhadap Kinerja Karyawan (Y). Gaya kepemimpinan merupakan proses memengaruhi dan menginspirasi orang lain untuk bekerja demi mencapai tujuan utama dan kemudian dapat memberikan kekuatan dan kebebasan untuk mencapainya.Gaya kepemimpinan dapat berupa teknik untuk mengatur manajemen sumber daya manusia.Seorang pemimpin dalam organisasi harus dapat menciptakan integrasi yang serasi dengan para bawahannya juga termasuk dalam membina kerjasama, mengarah dan mendorong gairah kerja para bawahannya sehingga tercipta niat dan usaha (kinerja) yang maksimal juga didukung oleh fasilitasfasilitas organisasi untuk mencapai sasaran organisasi.Hal ini memperkuat hasil penelitian dari Dewi Sandy Trang (2013) yang menemukan bahwa gaya kepemimpinan dan budaya organisasi berpengaruh positif dan signifikan terhadap kinerja karyawan (Studi pada Perwakilan BPKP Provinsi Sulawesi Utara).

\section{Pengaruh Motivasi terhadap Kinerja Karyawan}

Secara parsial dalam penelitian ini menunjukkan adanya pengaruh positif dan signifikan antara Motivasi $\left(\mathrm{X}_{2}\right)$ terhadap Kinerja Karyawan (Y).motivasi juga merupakan faktor yang mempengaruhi kinerja karyawan. Seorang pemimpin harus mampu memberikan motivasi kepada bawahan agar dapat bekerja dengan baik dan efektif. Pemimpin mempunyai kaitan yang erat dengan motivasi, sebab keberhasilan seorang pemimpin dalam menggerakkan orang lain dalam mencapai tujuan yang telah ditetapkan sangat bergantung kepada kewibawaan, dan juga pemimpin itu menciptakan motivasi di dalam diri setiap orang bawahan, kolega maupun atasan pemimpin itu sendiri. Hal ini memperkuat hasil penelitian dari Bryan Johannes Tampi (2014) yang menemukan bahwa gaya kepemimpinan dan motivasi berpengaruh positif dan signifikan terhadap kinerja karyawan pada Pt. Bank Negara Indonesia, Tbk (regional Sales Manado).

Pengaruh Gaya Kepemimpinan Dan Motivasi Terhadap Kinerja Karyawan

Secara simultan Gaya Kepemimpinan $\left(\mathrm{X}_{1}\right)$ dan Motivasi $\left(\mathrm{X}_{2}\right)$ memiliki pengaruh positif dan signifikan terhadap Kinerja Karyawan (Y).Salah satu pendekatan dalam upaya meningkatkan kinerja karyawan tersebut dapat dilakukan melalui praktik gaya kepemimpinan yang sesuai, motivasi juga merupakan faktor yang mempengaruhi kinerja karyawan. Seorang pemimpin harus mampu memberikan motivasi kepada bawahan agar dapat bekerja dengan baik dan efektif.Hal ini memperkuat hasil penelitian dari Bambang Irjanto dan Herman Setiawan (2016) yang menemukan bahwa gaya kepemimpinan dan motivasi memiliki pengaruh yang positif dan signifikan terhadap kinerja karyawan secara simultan pada Industri Umkm di wilayah D.I. Yogyakarta.

\section{Simpulan}

Berdasarkan pengujian secara parsial diketahui bahwa variabel gaya 
kepemimpinan dan motivasi memiliki pengaruh yang positif dan signifikan terhadap variabel kinerja karyawan. Pengujian secara simultan juga membuktikan bahwa variabel gaya kepemimpinan dan motivasi memiliki pengaruh yang positif dan signifikan terhadap variabel kinerja karyawan. Dengan persamaan regresi linier berganda yang didapatkan $\mathrm{Y}=1,382+$ $0,516 X_{1}+0,458 X_{2}$ Kontribusi dua variabel dapat diketahui dari besarnya nilai determinasi $72,2 \%$ sedangkan $27,8 \%$ lainnya dipengaruhi oleh variabel lain yang tidak diteliti.

\section{Saran}

Untuk dapat meningkatkan
kinerja karyawan maka pihak pimpinan perusahaan hendak dapat memperbaiki Gaya Kepemimpinan kearah yang lebih baik lagi.Salah satunya memperbaiki komunikasi dengan bawahan, agar tercipta komunikasi yang efektif, dan pimpinan dalam menyampaikan informasi baik berupa perintah atau instruksi lebih tepat kepada sasarannya agar tidak menimbulkan suatu konflik, karena pimpinan adalah penyalur berbagai informasi.sehingga mampu menciptakan kinerja yang baik.Berkaitan dengan motivasi kerja hendaknya para pemimpin yang ada agar lebih meningkatkan motivasi yang lebih tinggi kepada karyawan guna terciptanya kinerja karyawan yang baik. Salah satunya mengenai tanggapan responden tentang kenaikan jabatan untuk karyawan yang berprestasi yang rata-rata skornya paling rendah, pada permasalahan ini sebaiknya pimpinan bisa memberikan Promosi Jabatan serta bonus/kenaikan gaji bagi karyawan yang berprestasi untuk meningkatkan kinerja karyawan agar karyawan bisa melakukan pekerjaan dengan penuh tanggung jawabsehingga ke depan karyawan akan merasa termotivasi untuk bekerja lebih baik.

\section{REFERENSI}

AA. Anwar Prabu Mangkunegara, 2013,Manajemen Sumber
Daya Manusia
$\begin{aligned} & \text { Perusahaan, Remaja } \\ & \text { Rosdakarya, Bandung. }\end{aligned}$

Amirullah dan Budiyono Haris. 2004. Pengantar Manajemen. Yogyakarta: Graha Ilmu.

Andri Feriyanto dan Endang Shyta Triana. 2015.Pengantar Manajemen.

Kebumen: Mediatera.

B. Uno, Hamzah. 2008.Teori Motivasi dan Pengukurannya, Jakarta : Bumi

Aksara.

Bambang Irjanto, Herman Setiawan tahun.2016.Pengaruh Gaya Kepemimpinan

Dan MotivasTerhadap Kinerja

Karyawan Pada Industri

Umkm Di Wilayah D.I.

Yogyakart.Jurnal

MAKSIPRENEUR, Vol. V, No. 2, Juni 2016, hal. $15-26$.

Bangun, Wilson. 2012. "Manajemen Sumber Daya Manusia". Jakarta: Erlangga.

Bryan Johannes Tampi. 2014. "Pengaruh Gaya Kepemimpinan Dan Motivasi 
Terhadap Kinerja Karyawan Pada Pt. Bank Negara Indonesia,Tbk (Regional Sales Manado)". Journal "ActaDiurna" Volume 3.No.4.

Dewi Sandy Trang. 2013. "Gaya Kepemimpinan Dan Budaya Organisasi

Pengaruhnya Terhadap Kinerja Karyawan (Studi pada Perwakilan BPKP Provinsi Sulawesi Utara)".Jurnal EMBA 1(3) : 208-216.

Catatan : 1(3) : 208-216 berarti volume 1 nomor 3 halaman 208-216.

Gomes, Faustino Cardoso. 2003.Manajemen Sumber Daya Manusia. Edisi

Kedua.Penerbit Andi Offset, Yogyakarta.

Handoko, T., Hani, 1996, Manajemen dan Sumber Daya Manusia, Yogyakarta,

Liberty.

Hani. T. Handoko (2007). Mengukur kepuasan kerja. Jakarta. Jakarta. Erlangga.

Hasibuan, Malayu S.P, 2003, Manajemen Sumber Daya Manusia, Edisi Revisi.

\section{Manajemen Dasar, Pengertian, dan Masalah,Edisi \\ Revisi, Bumi Aksara: Jakarta.}

Heidjrachman\&SuadHusnan. 2002. Manajemen Personalia.Edisi 4.
Hersey, 2004.Kunci SuksesPemimpin Situasional.Jakarta Delaprasata.

Iskandar. 2008. Metodologi Penelitian Pendidikan dan Sosial (Kuantitatif dan

Kualitatif).Jakarta: GP Press.

Nawawi, Hadari. 2003. Kepemimpinan

Mengefektifkan Organisasi. Yogyakarta:

Gajah Mada University Press.

Purwanto. 2011. Evaluasi Hasil Belajar. Yogyakarta: Pustaka Pelajar.

Riduwan. 2005. Belajar Mudah Penelitian Untuk Guru, Karyawan dan Peneliti Pemula, Bandung :Alfabeta.

SittyYuwalliatin. 2006.Pengaruh Budaya Organisasi, Motivasi dan Komitmen

Terhadap Kinerja Serta Pengaruhnya Terhadap Keunggulan Kompetitif Dosen Unissula Semarang.Jurnal Ekonomi dan Bisnis, Vol. 7 No. 2, Juli, p. 241-256.

Sjafri dan Aida Vitayala Hubies.(2007). Manajemen Mutu Sumber Daya Manusia. Bogor: Ghalia Indonesia.

Sudjana, Nana. 2008. Penilaian Hasil Proses Belajar Mengajar. Bandung: PT Remaja Rosdakarya. 
Sugiyono 2001, Metode Penelitian Administrasi, $\quad$ Penerbit Alfabeta Bandung.

Tika, P. (2006). Budaya Organisasi Dan Peningkatan Kinerja Perusahaan.

Tjiptono. (2006). Manajemen Sumber Daya Manusia Untuk Perusahaan: Dari
Teori Ke Praktik. Jakarta: Raja Grafindo.

VeithzalRivai, 2004, "Manajemen Sumber Daya Manusia Untuk Perusahaan, Cetakan Pertama, Jakarta, PT. Raja Grafindo Persada. 